\title{
Plasticity influencing the light compensation point offsets the specialization for light niches across shrub species in a tropical forest understorey
}

\author{
Frank J. Sterck ${ }^{1 *}$, Remko A. Duursma ${ }^{2}$, Robert W. Pearcy ${ }^{3}$, Fernando Valladares ${ }^{4}$, \\ Mikolaj Cieslak ${ }^{5}$ and Monique Weemstra ${ }^{1,2}$ \\ ${ }^{1}$ Forest Ecology and Forest Management Group, Wageningen University, P.O. Box 47, 6700 AA, Wageningen, The \\ Netherlands; ${ }^{2}$ Hawkesbury Institute for the Environment, University of Western Sydney, Locked Bag 1797, Penrith, \\ 2751, NSW, Australia; ${ }^{3}$ University of California, Davis One Shields Avenue Davis, CA 95616, USA; ${ }^{4}$ Museo Nacional \\ de Ciencias Naturales CSIC, Serrano 115 dpdo, E-28006 Madrid, Spain; and ${ }^{5}$ INRIA project-team Virtual Plants UMR \\ AGAP, INRA UR 1115 Plantes et Systèmes de Culture Horticoles, 95 rue de la Galéra, 34095 Montpellier Cedex 5 , \\ France
}

\section{Summary}

1. Shade tolerance can be defined as the light level at which plants can survive and possibly grow. This light level is referred to as the whole-plant light compensation point (LCP). The LCP depends on multiple leaf and architectural traits. We are still uncertain how often interspecific trait differences allow species to specialize for separate light niches, as observed between shade-tolerant species and light-demanding species. Alternatively, trait plasticity may allow many species to grow in similar light conditions.

2. We measured leaf and architectural traits of up to 1.5 -year-old seedlings of 15 sympatric Psychotria shrub species grown at three light levels. We used a 3D plant model to estimate the impacts of leaf traits, architectural traits and plant size on the whole-plant light compensation point $\left(\mathrm{LCP}_{\text {plant }}\right)$. Plant growth rates were estimated from destructive harvests and allometric relationships.

3. At lower light levels, plants of all species achieved a lower leaf light compensation point $\left(\mathrm{LCP}_{\text {leaf }}\right)$. The light interception efficiency (LIE), an index of self-shading, decreased with increasing plant size and was therefore lower in high-light treatments where plants grew more rapidly. When corrected for size, LIE was lower in the low-light treatment, possibly as a result of lower investments in woody support. Species did not show trade-offs in growth under low- and high-light conditions, because species with the greatest plasticity in $\mathrm{LCP}_{\text {plant }}$ and underlying traits $\left(\mathrm{LCP}_{\text {leaf }}\right.$ and $\left.\mathrm{LIE}\right)$ achieved the highest growth rates at lower light levels.

4. Synthesis. The interspecific differences in $\mathrm{LCP}_{\text {plant }}$ did not result in a growth or survival trade-off between low- and high-light conditions. Instead, these differences were more than offset by the greater plasticity in $\mathrm{LCP}_{\text {plant }}$ in some species, which was driven by greater plasticity in both leaves and architecture. The most plastic species achieved the fastest growth at different light levels. The results show that plasticity largely neutralizes the separation of light niches amongst species in this forest understorey genus and imply that differential preferences of species for either gaps or forest understorey occur in later life phases or are driven by other stress factors than low light alone.

Key-words: ecophysiology, leaf trait, light acclimation, light interception efficiency, light niche, plant architecture, self-shading, shade tolerance, tropical forest, Y-plant

\section{Introduction}

The shade tolerance of a plant can be characterized by the minimum light level required for survival and growth. This

*Correspondence author. E-mail: frank.sterck@wur.nl light level is referred to as the whole-plant light compensation point or LCP (Horn 1971; Givnish 1988; Valladares \& Niinemets 2008). The LCP depends on multiple leaf and architectural traits (Baltzer \& Thomas 2007). When plants of different species differ in these traits, they may specialize for separate light niches (Sterck et al. 2011). Plants, however, 
typically exhibit considerable plasticity in many traits in response to different light environments. When such plasticity allows species to survive and grow in a range of light conditions, it potentially hinders the separation for light niches among many species.

The carbon gain hypothesis states that traits that enable greater carbon gain under shaded conditions increase the shade tolerance of a plant (Givnish 1988). This hypothesis predicts that plants with a lower LCP can tolerate deeper shade than plants with a higher LCP (Valladares \& Niinemets 2008). Plants may achieve a low LCP by a low leaf compensation point $\left(\mathrm{LCP}_{\text {leaf }}\right)$, which depends on the light response curve of leaf photosynthesis, as well as by displaying the leaves such that the amount of self-shading among leaves is reduced (Horn 1971). If these properties result in a low assimilation capacity of plants under high-light conditions (Sterck et al. 2011), the species that specialises for shade may have slower growth and lower competitive ability at such high-light conditions (Kobe 1996; Sterck, Poorter \& Schieving 2006). Moreover, while plants grow, the higher carbon costs due to an increase in supporting tissue enhance the LCP. Leaf physiological traits, plant architecture and size influence shade tolerance, but it remains a challenge to separate their effects on possible shade tolerance/ growth trade-offs across species, because they are functionally interdependent (Pearcy, Muraoka \& Valladares 2005) and plastic in their response to heterogeneous light conditions (Valladares et al. 2000; Sterck \& Bongers 2001).

Plants show a number of qualitatively predictable plastic responses to variation in light. In deep shade, they reduce the biomass cost of light interception by producing leaf area at lower leaf mass costs (i.e. increased specific leaf area) (Walters \& Reich 1999; Poorter et al. 2009), and they reduce the amount of self-shading by producing leaves at a slower pace and displaying less leaf area (Poorter \& Werger 1999). Such plastic responses may allow plants to maximize carbon gain with changing light conditions, despite the costs of tissue replacement. Yet, such plastic responses cannot completely offset the species-specific trait impacts on growth and survival and, in turn, on their specialization for different light habitats (Sterck et al. 2011). However, studies rarely account for plastic responses explicitly and their evidence for specialization may partially rely on the inclusion of extremely shade tolerant and intolerant canopy tree species (Markesteijn et al. 2011). We therefore cannot exclude the possibility that plasticity in leaf traits and architecture largely neutralizes niche separation among many species, or within functional groups (e.g. Hubbell 2005, 2006).

The objective of this study was to examine for a range of species how leaf traits, architecture and size impact upon their shade tolerance, and whether this contributes to a trade-off with growth. We conducted a growing house experiment with three different light environments on 15 sympatric shrub species of the genus Psychotria, which occur in a tropical forest understorey on Barro Colorado Island, Panama. We expect plants at high light to grow more rapidly and thus become larger and exhibit greater self-shading in denser crowns with a more clumped leaf distribution (Duursma et al. 2012), which would lead to higher LCP than plants grown at low light. When corrected for such size effects, however, we hypothesized that lowlight plants display their leaves by spacing and orientating them such that they acquire light more effectively than high-light plants, but leaf spacing might be constrained by low investments in supporting internodes or petioles (Pearcy, Muraoka \& Valladares 2005). We also tested two hypotheses for acrossspecies differences. First, in line with the carbon gain hypothesis, we predicted that plants at low light will grow more rapidly for species that achieve a lower LCP compared to species with a higher LCP. Second, differences in LCP either drive a tradeoff in growth between low- and high-light conditions or, alternatively, such a trade-off is offset by the plastic responses in LCP and underlying traits.

\section{Materials and methods}

\section{EXPERIMENT}

We compared LCP with leaf traits, architectural traits, size and growth for the seedlings of 15 Psychotria species: P. acuminata, P. brachiata, P. chagrensis, P. emetica, P. gracilifora, P. grandis, P. horizontalis, P. ipecacuanha, P. limonensis, P. marginata, P. micrantha, P. pittieri, P. psychotriifolia, P. pubescens, P. racemosa. Although from the same genus and life-history group (shrubs), these species are known to largely differ in traits and light habitat preferences (Valladares et al. 2000). Therefore, they present an interesting case for testing trait impacts on LCP and growth under contrasting light levels. Individuals of all species were grown at three different light levels. Seeds were collected from 10 reproductive adult plants per species. The seeds were sown within a week of collection after manually removing the pulp in 50-L pots containing a 50:50 mix of forest topsoil and river sand. Germination time varied across species with seedlings of all species being established after 5 weeks. After those 5 weeks, the largest individual per pot was selected for the experiment, and other seedlings were removed. After this, we started the experiment simultaneously for all seedlings, with three replicate benches (with shade cloth) for each of the three light treatments, and two seedlings of each species per bench. Plants were grown in lowlight (LL), medium-light (ML) and high-light (HL) treatments with average photosynthetic photon flux density (PPFD) percentages relative to fully exposed sites of $1.4 \%( \pm 0.2), 8.8 \%( \pm 1.1)$ and $31.3 \%$ $( \pm 3.7)$, respectively (Valladares et al. 2000). The treatments span the light levels encountered from the closed forest understorey (1.5-9.5\%, $\pm 0.3-0.4)$ to large treefall gaps $(35.3 \pm 6.3 \%)$ (Valladares et al. 2000). The focus of this study is on the impacts of these PPFD differences, and possible impacts of associated differences in the light spectrum were not considered. All plants were allowed to grow for 1.5 year, but the fast growing plants were harvested earlier when their crown reached the shading cloth. Root binding by pot boundaries was not observed for any of the plants, implying that root growth was not limited by space. Ultimately, seedlings were grown for 6 months to 1 year in the ML and HL treatment, and for ca. 18 months in the LL treatment. We used all plants in our analyses.

\section{MEASURED PLANT TRAITS}

Before harvest, light response curves of photosynthesis were measured with a portable IRGA system, model Ciras-I (PP-systems, Hitchin Herts, UK) on recently expanded leaves. From these curves, 
we calculated the area-based leaf assimilation rate at saturating light $\left(\mathrm{A}_{\text {area }}, \mu \mathrm{mol} \mathrm{m} \mathrm{m}^{-2} \mathrm{~s}^{-1}\right.$ ) and the leaf light compensation points $\left(\mathrm{LCP}_{\text {leaf }}, \mu \mathrm{mol} \mathrm{m} \mathrm{m}^{-2} \mathrm{~s}^{-1}\right)$ as the PPFD where $\mathrm{A}_{\text {area }}$ is zero. The area-

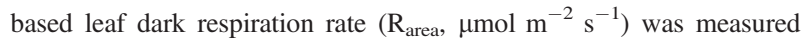
with a leaf disk oxygen electrode (Hansatech, Norfolk, UK). Absorption, reflectance and transmission of PPFD were measured, using a spectro-radiometer (LI-COR instruments, Valladares, Skillman \& Pearcy 2002). The values used were the mean response of three leaves per species per treatment. After harvest, we measured the total leaf mass $(\mathrm{g})$, total leaf area $\left(\mathrm{m}^{2}\right)$, the supporting stem biomass (stems, branches and petioles, g) and the root biomass (g). We calculated the leaf mass per unit leaf area (LMA, $\mathrm{g} \mathrm{m}^{-2}$ ), the leaf massbased assimilation rate $\left(\mathrm{A}_{\text {mass }}, \mu \mathrm{mol} \mathrm{g} \mathrm{g}^{-1} \mathrm{~s}^{-1}\right)$, the leaf mass-based respiration rate $\left(R_{\text {mass }}, \mu \mathrm{mol} \mathrm{g} \mathrm{s}^{-1}\right.$ ), the leaf area to total plant mass ratio $\left(\mathrm{LAR}, \mathrm{m}^{2} \mathrm{~g}^{-1}\right.$ ) and the leaf mass to total plant mass ratio (LMR, $\mathrm{g} \mathrm{g}^{-1}$ ).

\section{SIMULATED PLANT TRAITS}

All plants were digitized in approximately 6-week (ML and HL) or 12-week (LL) intervals using a FASTRAK ${ }^{\circledR}$ 3D-digitizer (Polhemus, Colchester, VT, USA). Following the protocol described by Pearcy, Duursma \& Falster (2011), each leaf position (base of petiole, base of leaf blade and two points of the leaf) and stem section position was recorded with a pointing device, which translated into 3D coordinates by the magnetic digitizer. Digitization ceased when HL and ML plants approached the shade cloth top of the enclosure at which time the plants were harvested. Digitization of the LL plants continued for 1.5 years at which time the experiment was terminated. These measurements were used to reconstruct changes in the 3D architecture and photosynthesis of the plants during their development using a new implementation of the Y-plant model (Pearcy \& Yang 1996). Total crown photosynthesis was estimated by integrating the diurnal courses of photosynthesis and respiration of individual leaves, which were estimated from the species- and treatment-specific light response curves and the estimated diurnal courses in PPFD for each leaf (see Pearcy, Duursma \& Falster 2011 for details). The diurnal root respiration rate was calculated from the product of the root mass and an assumed root mass-based respiration rate of $5 \mathrm{nmol} \mathrm{g}^{-1} \mathrm{~s}^{-1}$, based on theory by Penning de Vries (1975) and used in tropical seedling simulations (Veneklaas and Poorter 1998). Root biomass was estimated at every interval, using the same root-shoot ratio as measured at the time of harvest. The diurnal stem segment respiration was calculated as the product of stem segment mass and stem mass-based respiration rate of $2 \mathrm{nmol} \mathrm{g}^{-1} \mathrm{~s}^{-1}$ (Veneklaas and Poorter 1998). The same stem mass- and root mass-based respiration rates were used in all simulations. Our simulations do thus not account for possible differences in mass-based respiration across treatment or species. Ultimately, net photosynthesis of each plant was calculated as the difference between photosynthesis and the sum of leaf, stem and root respiration.

Compared to the Y-plant model description by Pearcy \& Yang (1996), we used a new implementation of Y-plant (Duursma et al. 2012), which uses the QuasiMC ray-tracer developed by Cieslak et al. (2008). The ray-tracer estimates the amount and quality (spectral composition) of light reaching each leaf by simulating the path of photons from a light source towards the virtual plant canopy and takes into account the scattering of radiation due to reflection and transmission of light by the leaves. For our species and treatments, measured light absorption in the PAR waveband varied between 0.65 and 0.91 , and reflection between 0.058 and 0.19 . Using the new implementation (YplantQMC, see www.remkoduursma.com/yplantqme), we calculated two measures of light interception. The light interception efficiency (LIE) was calculated as the ratio of plant light absorption over a day (assuming only diffuse radiation), divided by the light absorption of a horizontal surface with the same area. We also calculated STAR (Duursma et al. 2012), the hemi-spherically averaged ratio of displayed leaf area to plant leaf area. While the LIE takes into account the measured leaf optical properties (absorption, reflection and transmission), $\overline{\text { STAR }}$ does not.

We also simulated light response curves of total plant photosynthesis for all digitized plants using YplantQMC. From these curves, we estimated the plant light compensation point $\left(\mathrm{LCP}_{\text {plant }}\right)$ as the PPFD at which total net plant photosynthesis was zero. The $\mathrm{LCP}_{\text {plant }}$ accounts for the photosynthetic responses by leaves, impact of selfshading as related to plant architecture, and maintenance respiration costs by leaves, stem segments and roots. We assume that $\mathrm{LCP}_{\text {plant }}$ is a useful proxy for the shade tolerance, because it estimates the light level at which the carbon budget of the plant is zero.

The biomass growth rate was calculated for each plant. The 3D reconstructed plants at intervals of 6 (ML and HL treatment) to 12 weeks (LL treatment) provided estimates of the total leaf area (and mass by using measurements of LMA) and the support structure mass (above-ground woody material) per plant. Assuming a fixed root-toshoot ratio as measured at the time of harvest, we also estimated the corresponding changes in the root biomass per plant. Subsequently, we estimated the biomass of each plant on day 100 of the experiment, using interpolations based on a monotonically increasing spline. We then averaged the growth rates over the first 100 days to obtain a measure of biomass growth rate for comparisons across treatments and species.

\section{DATA ANALYSIS}

We first analysed the plastic responses of plants to different light treatments. We compared leaf traits, architectural traits and $\mathrm{LCP}_{\text {plant }}$ across the three light treatments, using linear mixed-effects models with species as a random factor, and adding individual as random factor for $\mathrm{LCP}_{\text {plant }}$ and LIE. For all digitized plants, we show the developmental trajectories in $\mathrm{LIE}$ and $\mathrm{LCP}_{\text {plant }}$ with increasing total leaf area. The allometric relationships between total leaf area, total plant mass and woody plant mass were compared across the light treatments, with standardized major axis using the smatr package (Warton et al. 2012) in R (R Development Core Team 2012).

We tested whether the decrease in STAR with ontogeny was related to an increase in crown density (measured as the ratio of total leaf area to crown surface area, see Duursma et al. 2012), or a decrease in leaf dispersion (i.e. more clumped foliage for larger plants). To do this, we fit the model of STAR from Duursma et al. (2012) to the 559 digitized plants in the data set, which is given by,

$\overline{\mathrm{STAR}}=\frac{\phi A_{C}}{\beta^{E} A_{L}}\left(1-e^{-k \beta^{E} A_{L} / \phi A_{C}}\right)$

eqn 1

where $A_{C}$ the crown surface area $\left(\mathrm{m}^{2} \mathrm{~m}^{-2}\right), \mathrm{A}_{\mathrm{L}}$ plant leaf area $\left(\mathrm{m}^{2}\right)$, $\beta$ a measure of leaf dispersion (summarizing the distribution of leaves within the canopy volume), $K=0.5$ (a constant), and $\phi$ and $\varepsilon$ are empirical parameters determined from fitting the model to data. The model fit the data very well $\left(R^{2}=0.89\right)$. For each plant, we estimated leaf dispersion and crown density at the first and last digitisations and calculated the ontogenetic change in both variables from these two points (the length of time therefore varied between plants). Then, we estimated the expected change in $\overline{\mathrm{STAR}}$ using the fitted model (eqn 
1), using either the measured change in leaf dispersion, or the measured change in crown density. For both cases, all other variables were held constant. This way, we were able to separate the effects of ontogenetic patterns in crown density and leaf dispersion on the overall STAR of the plant.

To test for differences in leaf and whole-plant traits across species, we averaged the leaf and architectural traits for all species in each light treatment at time of harvest. We calculated the plasticity in each trait as the absolute difference between the species-specific trait value at HL and LL. Some of the characteristics were $\log _{10}$ transformed to improve the linearity and the normality of the investigated relationships. We used linear regression analysis to show how $\mathrm{LCP}_{\text {plant }}$ differences were explained by $\mathrm{LCP}_{\text {leaf }}$, LIE and LMR and to show how biomass growth differences resulted from differences in $\mathrm{LCP}_{\text {plant }}$ and in the plasticity of $\mathrm{LCP}_{\text {plant }}$ for each light treatment. These regression analyses were performed for each light treatment separately.

\section{Results}

\section{INTRASPECIFIC TRENDS}

Some plant traits differed between the light treatments (Fig. 1). LMA was lowest at the LL level, intermediate at ML level and highest at the HL level (Fig. 1e). As $R_{\text {mass }}$ and $A_{\text {mass }}$ were nearly constant for the different light treatments (Fig. 1a,b), the $\mathrm{A}_{\text {area }}, \mathrm{R}_{\text {area }}$ and $\mathrm{LCP}_{\text {leaf }}$ increased under higher light levels (only shown for $\mathrm{LCP}_{\text {leaf }}$, Fig. 1f), in concordance with the pattern in LMA (Fig. 1e). LMR was higher at LL than at ML or HL, and LAR decreased from the LL to HL treatment (Fig. 1c,d). The LIE was lower at higher light levels (Fig. 1g), and the $\mathrm{LCP}_{\text {plant }}$ and variation in $\mathrm{LCP}_{\text {plant }}$ were higher at higher light levels (Fig. 1h).

The plants exhibited a wide range in LIE (between 0.4 and 0.9 , Fig. 2a). Plants with leaf area $<0.001 \mathrm{~m}^{2}$ or plant mass $<\sim 0.1$ gram, with some plants supporting two leaves only, started with LIE close to 0.9 (Fig. 2a), but when they grew larger, LIE decreased, even to levels close to 0.4 in some plants with leaf area $>0.1 \mathrm{~m}^{2}$ or with plant mass $>10 \mathrm{~g}$. The drop in LIE with increasing size was less in LL plants than in ML or HL plants. Remarkably, LL plants had a lower LIE than ML plants (linear mixed-effect models, $P=0.027$, $N=360$ ) and HL plants (linear mixed-effect models, $P<0.001, N=363$ ), when compared at the same leaf area. ML and HL plants did not differ in LIE at the same leaf area.

$\mathrm{LCP}_{\text {plant }}$ increased with size (Fig. 2b). Over the full size trajectory, approximately half of the LL plants had a lower $\mathrm{LCP}_{\text {plant }}$ than any of the ML or HL plants. The ML and HL plants show larger overlap in $\mathrm{LCP}_{\text {plant, }}$ also when corrected for size (Fig. 2b).

LL plants did not grow to the same mass or leaf area as did ML or HL plants, not even when 18 month-old LL plants were compared with 6-12-month-old ML or HL plants (Fig. 2, also illustrated by Fig. S1). Over their whole plant mass trajectory, LL plants produced more leaf area per aboveground plant mass (leaf and per woody segment mass, Fig. 3a) or woody segment mass only (Fig. 3b) than ML and HL plants (per Table 1).
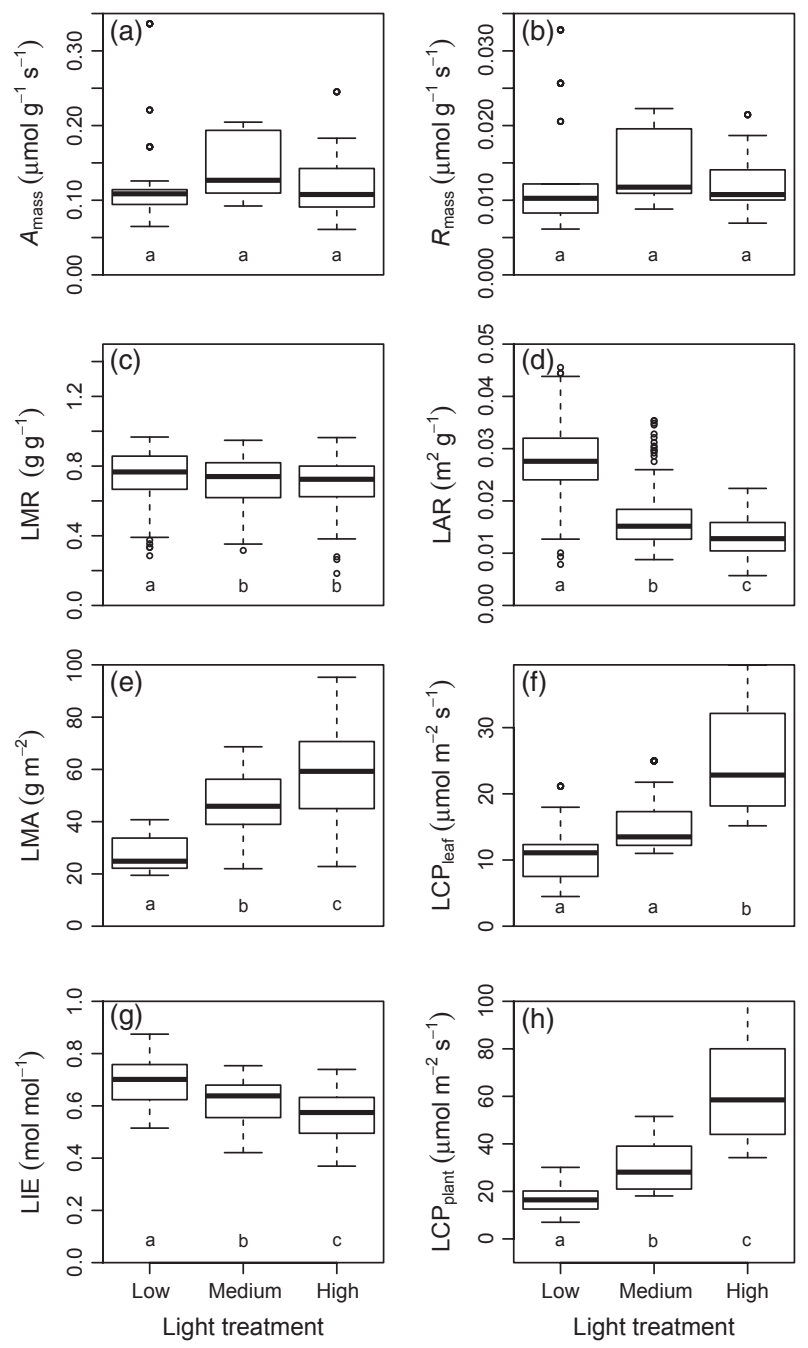

Fig. 1. Functional traits of seedlings in three light conditions for 15 sympatric Psychotria plant species from a tropical rain forest in Panama. The variation refers to across species variation, as trait values were averaged per species and light treatment. For trait names and light treatments, see Methods section. Different letters below the boxes indicate significant differences in traits between light treatments $(P<0.05)$, using linear mixed-effects models with species and individual (the latter for $\mathrm{LCP}_{\text {plant }}$ and LIE only) as random factors. All traits were measured at the time of harvest of the individuals.

At the start of the experiment, LL plants had a lower $\mathrm{LCP}_{\text {leaf }}$ and $\mathrm{LCP}_{\text {plant }}$ than ML and HL plants. At this stage, all LL plants and some ML plants had a $\mathrm{LCP}_{\text {plant }}$ that was similar to their $\mathrm{LCP}_{\text {leaf }}$ (Fig. 4a), but for all $\mathrm{HL}$ plants and the remaining $\mathrm{ML}$ plants, the $\mathrm{LCP}_{\text {plant }}$ was considerably higher than the $\mathrm{LCP}_{\text {leaf }}$. During the experiment, the $\mathrm{LCP}_{\text {plant }}$ approximately doubled for most plants (Fig. 4a), which was due to the gradual decline in LIE (Fig. 4b) and increasing investments in stem and roots as the plants increased in size. The decrease in LIE with increasing plant size is very similar to the decrease in STAR with size (see Fig. S2), which does not account for leaf optical properties (light reflection, absorption). The decrease in STAR with size was associated 

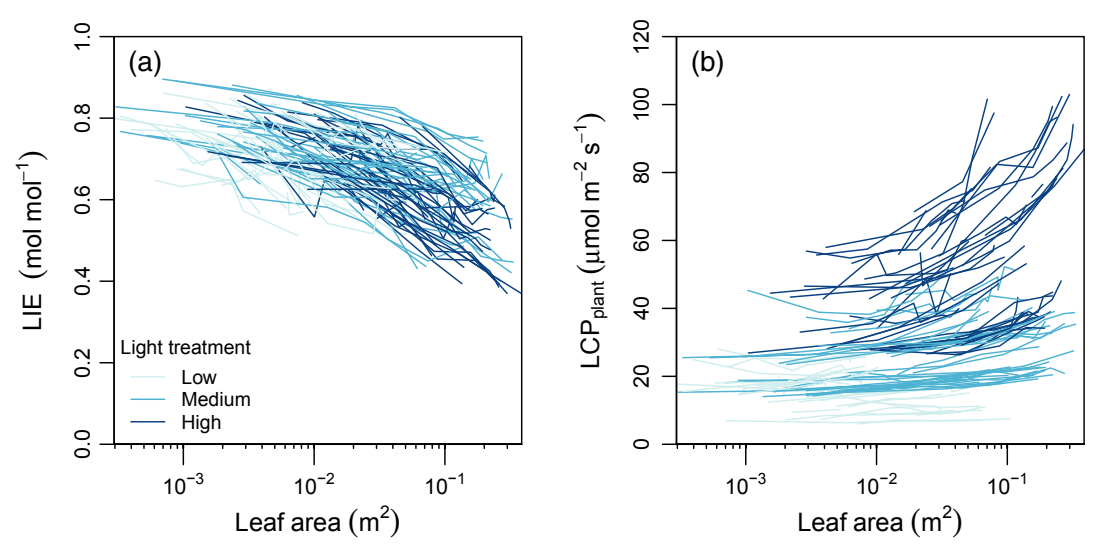

Fig. 2. Plant size impacts on (a) the light interception efficiency (LIE) and (b) plant light compensation point $\left(\mathrm{LCP}_{\text {plant }}\right)$ for seedlings in the three light treatments for 15 sympatric Psychotria plant species from a tropical rain forest in Panama. Each line refers to the developmental trajectory of an individual plant, from lower to higher leaf area. Note the $\log _{10}$ scale for the leaf area axis.

Fig. 3. Leaf area vs. plant biomass relationships for seedlings in three light treatments for 15 Psychotria species from a tropical rain forest in Panama. Note $\log _{10}$ scale for both axes. For statistical comparisons amongst light treatments, see Table 1.
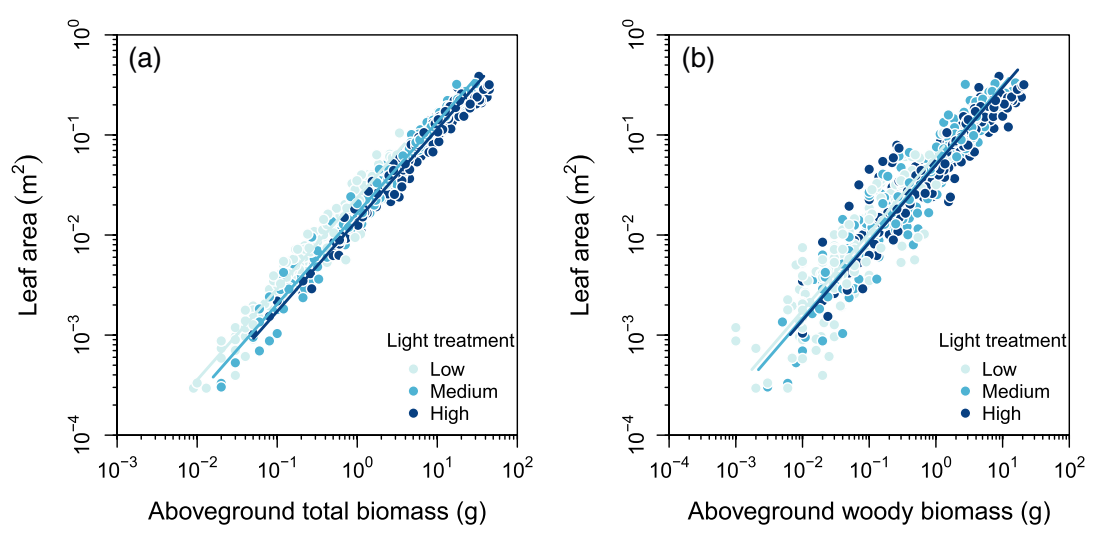

Table 1. Coefficients for the fits shown in Fig. 3, estimated with standardized major axis (SMA)

\begin{tabular}{llllll}
\hline Model & Treatment & $\mathrm{n}$ & $\mathrm{R}^{2}$ & $\mathrm{~b}_{0}(95 \% \mathrm{CI})$ & $\mathrm{b}_{1}(95 \% \mathrm{CI})$ \\
\hline Leaf area vs. plant & $\mathrm{LL}$ & 149 & 0.952 & $0.0236(0.0224-0.0248)^{\mathrm{a}}$ & $0.910(0.896-0.925)$ \\
biomass (see Fig. 3a) & $\mathrm{ML}$ & 196 & 0.977 & $0.0166(0.0160-0.0171)^{\mathrm{b}}$ & \\
& $\mathrm{HL}$ & 194 & 0.965 & $0.0140(0.0135-0.0146)^{\mathrm{c}}$ & $0.776(0.75-0.802)$ \\
Leaf area vs. woody & $\mathrm{LL}$ & 149 & 0.720 & $0.0624(0.0546-0.0714)^{\mathrm{a}}$ & \\
biomass (see Fig. 3b) & $\mathrm{ML}$ & 196 & 0.901 & $0.0522(0.0486-0.0561)^{\mathrm{b}}$ & \\
& $\mathrm{HL}$ & 194 & 0.864 & $0.05000 .0466-0.0536)^{\mathrm{b}}$ & \\
\hline
\end{tabular}

The models are of the form: Leaf area $=b_{0} \mathrm{M}^{b 1}$, where $\mathrm{M}$ is either total plant biomass, or woody plant biomass. For both models, one common slope $\left(b_{1}\right)$ was fit, because we aimed to test the effect of the light treatment on the elevation $\left(b_{0}\right)$ of the fit (and good fits were obtained using a single $b_{1}$ ). Letters following the $95 \%$ confidence interval $(\mathrm{CI})$ for $\mathrm{b}_{0}$ denote pair-wise significant differences $(\alpha=0.05)$. Low-light (LL) stands for LL treatment, medium-light (ML) for ML treatment and high-light (HL) for HL treatment.

with both a higher crown density (leaf area/crown surface area) and a more clumped leaf distribution (Fig. 5).

\section{INTERSPECIFIC PATTERNS}

As ML and HL plants had similar trait values but differed from LL plants, we focus the results for the species comparisons on plants at low and high light (Figs 6-8, see also Fig. $\mathrm{S} 3$ for ML plant results). The interspecific differences in $\mathrm{LCP}_{\text {plant }}$ were due to variation in $\mathrm{LCP}_{\text {leaf }}$ and $\mathrm{LIE}$, and not directly to plant size (as leaf area, not shown) and not to bio- mass partitioning (as LMR, see Fig. S4). In all cases, $\mathrm{LCP}_{\text {plant }}$ increased with a higher $\mathrm{LCP}_{\text {leaf }}$ (Fig. 6a,c), and also with a lower LIE at low light levels (Fig. 6b). In addition, the differences in the plasticity in $\mathrm{LCP}_{\text {plant }}$ across species resulted mainly from the plasticity in $\mathrm{LCP}_{\text {leaf }}$ rather than in LIE (Fig. 6e,f).

The species-specific growth rates at LL decreased with increasing $\mathrm{LCP}_{\text {plant }}$, though this was only marginally significant (Fig. 7a, see also for ML plants, SI Fig. 3). At HL, growth rates were not significantly affected by $\mathrm{LCP}_{\text {plant }}$ (Fig. 7b). HL plants benefited from a larger leaf area and 

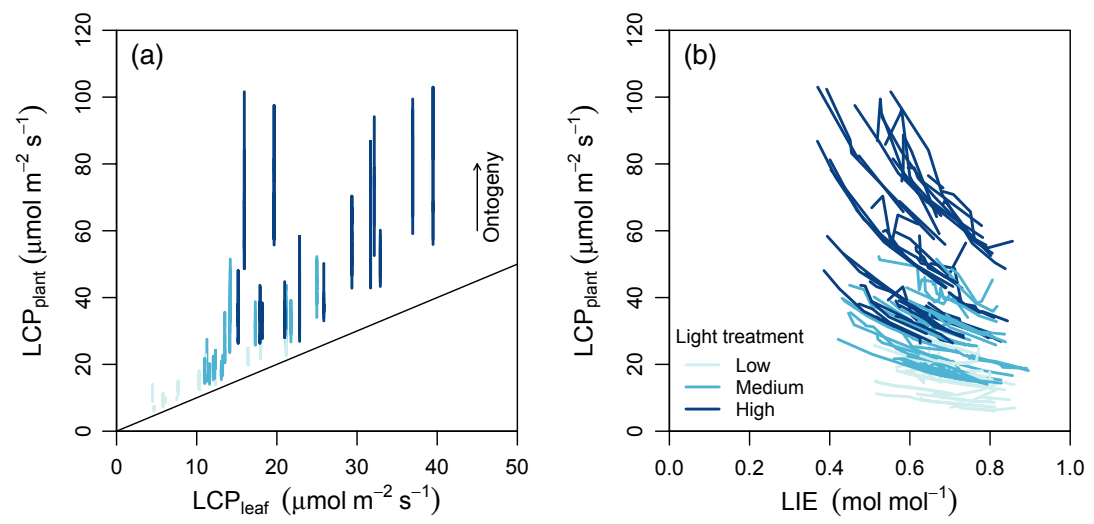

Fig. 4. The impact of (a) leaf and (b) architectural traits on $\mathrm{LCP}_{\text {plant }}$ for seedlings in three light treatments for 15 Psychotria species from a tropical rain forest in Panama. Every line visualises the development trajectory of an individual plant during the experiment, running from lower to higher $\mathrm{LCP}_{\text {plant }}$. The diagonal line in (a) is the 1:1 line.

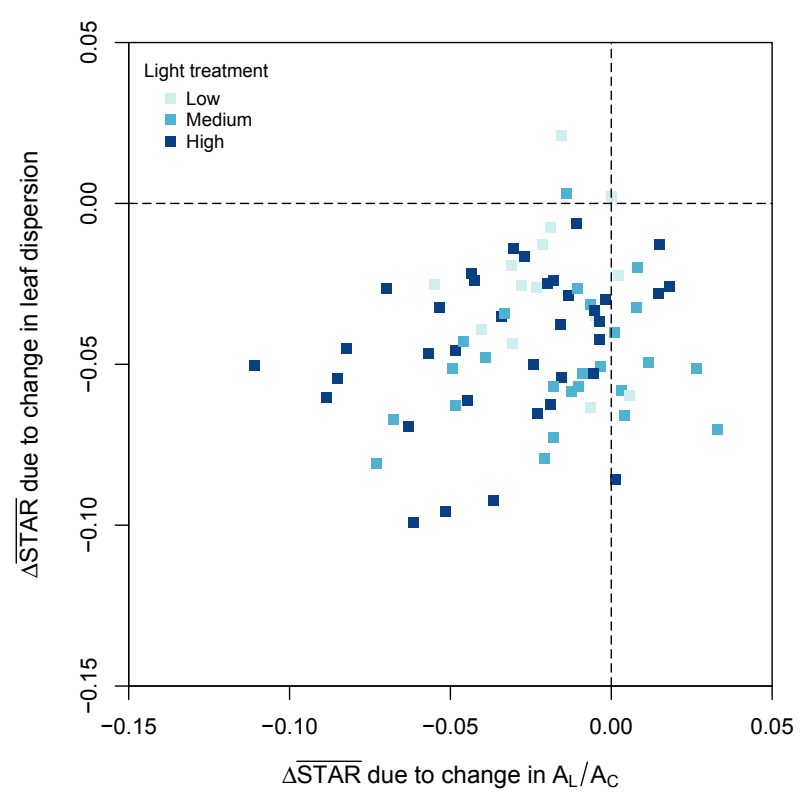

Fig. 5. The influence of architectural effects on changes in STAR (the hemi-spherically averaged ratio of displayed leaf area to plant leaf area). Change in STAR and underlying architectural changes were fitted for the change from the start of the experiment until the end at the time of plant harvest.

resultant greater photosynthetic capacity of the whole crown (not shown). The plasticity in $\mathrm{LCP}_{\text {plant }}$ positively impacted growth at LL (Fig. 7c). The plasticity may partially explain the coupling between growth rates at low and high light across species (Fig. 8).

\section{Discussion}

In this study, we show how the plasticity in whole plant light compensation points of 15 sympatric Psychotria species are affected by both leaf traits and whole-plant architecture. In recently established seedlings, $\mathrm{LCP}_{\text {plant }}$ was largely determined by $\mathrm{LCP}_{\text {leaf }}$, and varied fivefold across species and light treatments. At the end of the experiment, all seedlings approximately had doubled their $\mathrm{LCP}_{\text {plant }}$ due to a higher level of self-shading among leaves, which reduced LIE (Fig. 4). HL seedlings doubled their $\mathrm{LCP}_{\text {plant }}$ in $\sim 6-$ 12 months, whereas the much slower growing LL seedlings doubled their $\mathrm{LCP}_{\text {plant }}$ in $\sim 18$ months. These results suggest that seedlings reduce their shade tolerance considerably as they grow larger during their first year, even more so in exposed than shaded conditions.

Plants faced a lower LIE and higher $\mathrm{LCP}_{\text {plant }}$ as their crown developed (Fig. 2). LL plants decreased LIE and increased $\mathrm{LCP}_{\text {plant }}$ at a slower pace than HL plants due to their slower growth. The overall decline in the LIE with increasing plant size agrees with studies on seedlings of temperate deciduous trees (Delagrange et al. 2006) and rain forest evergreen trees (Lusk et al. 2011), and also with a global synthesis of 1831 plants of 124 species (Duursma et al. 2012). For our study plants, the decrease in LIE with larger size partially resulted from a higher leaf area/crown surface area (Fig. 5), which is in line with the greater level of leaf self-shading in larger plants reported by other studies (Farque, Sinoquet \& Colin 2001; Delagrange et al. 2006; but not generally in Duursma et al. 2012). Larger plants also decreased the dispersion of leaves (Fig. 5) (i.e. leaves in a more clumped distribution), which is consistent with a global data set analysis of Duursma et al. (2012). The lack of any decrease in the light capture efficiency with size in forest-grown Psychotria plants (Pearcy et al. 2004) probably resulted from random across-plant differences in recent growth conditions and growth rates.

In contrast to our expectation, LL plants tended to acquire light less efficiently than ML and HL plants, when we corrected for plant size in the analysis (Fig. 2a). LL plants increased their total leaf area per plant mass (Fig. 1d) via reduced investment in support mass (Fig. 1c and Fig. 2b) and, as shown by many studies (e.g. Poorter et al. 2009), by a lower LMA (Fig. 1e). This result is in line with a simulation study showing that optimum architectures (in terms of growth) could be one with shorter, thinner internodes allowing for a greater investment in leaf area while still maintaining sufficient biomechanical support and hydraulic capacity (Pearcy, Mur- 

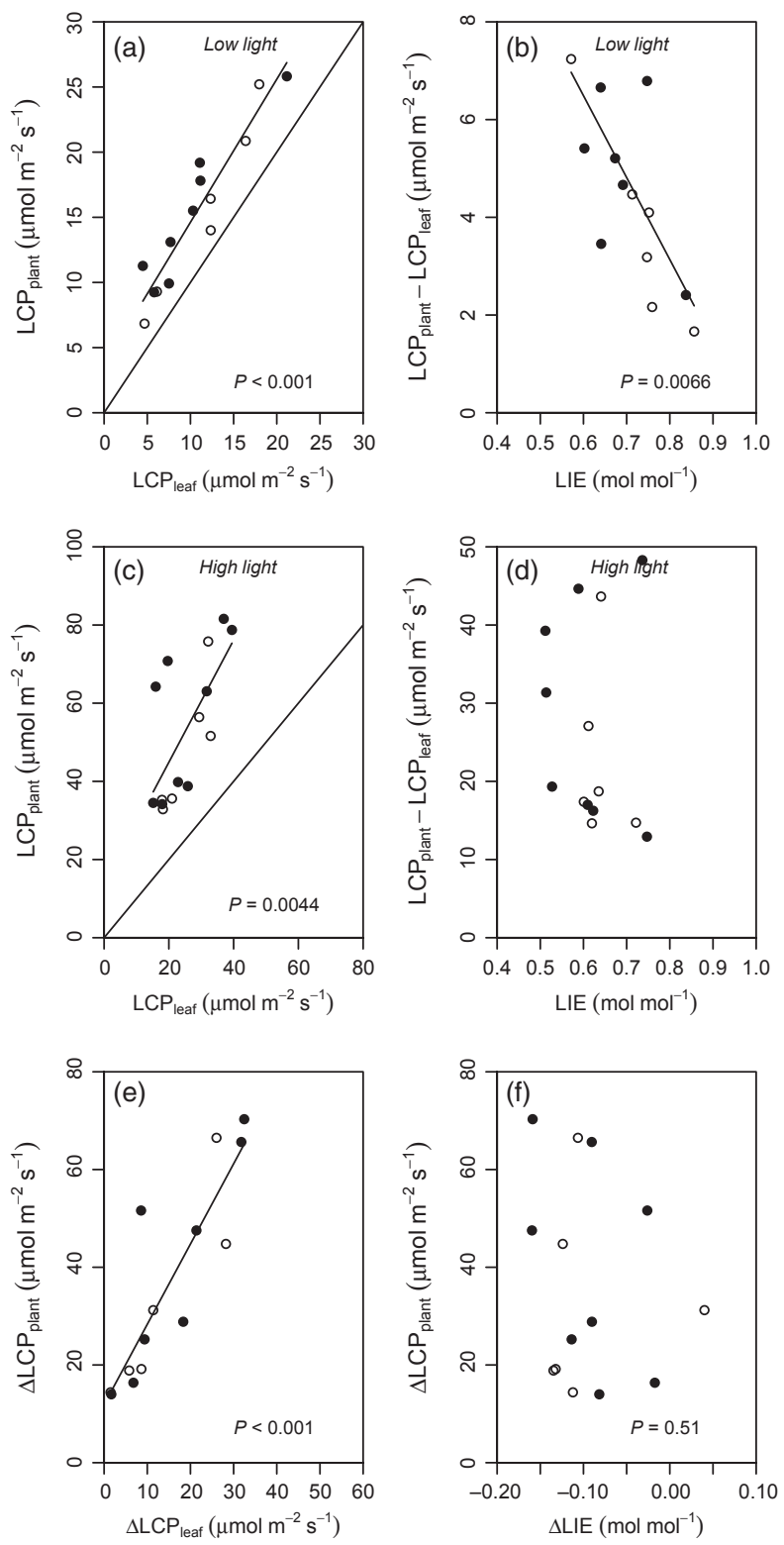

Fig. 6. The impact of the leaf compensation point $\left(\mathrm{LCP}_{\text {leaf }}\right)$ and light interception efficiency (LIE) on the plant light compensation point $\left(\mathrm{LCP}_{\text {plant }}\right)$ for seedlings of 15 Psychotria species, both in low and high light treatments. The impact of LIE is shown for the difference between the $\mathrm{LCP}_{\text {plant }}$ and $\mathrm{LCP}_{\text {leaf }}$. The impacts of the variation in traits $\left(\triangle \mathrm{LCP}_{\text {leaf }}\right.$ and $\left.\Delta \mathrm{LIE}\right)$ on variation in plant light compensation points $\left(\Delta \mathrm{LCP}_{\text {plant }}\right)$ are also shown. (Similar analyses for impacts of leaf mass to total plant mass ratio were insignificant, see Fig. S3). The significant linear trends are indicated with solid lines $(P<0.05)$. Species with a preference for gap (Valladares et al. 2000) are indicated by open circles, and those occurring in the forest understorey by solid black circles. See Fig. S2 (Supporting Information) for medium-light plant results.

aoka \& Valladares 2005). The positive effect of additional leaf area on carbon gain may more than offset the negative effect of increased self-shading (Pearcy, Muraoka \& Valladares 2005). The tendency of shaded plants to favour carbon returns by increasing leaf area over mass investments possibly also constrains the variation in LIE observed across species (e.g. Valladares, Skillman \& Pearcy 2002; Lusk et al. 2011).
Few studies report how leaf traits and crown architecture influence the light compensation points of whole plants (but see Baltzer \& Thomas 2007; Sterck et al. 2011). Within our light treatments, $\mathrm{LCP}_{\text {plant }}$ approximately doubled in $\mathrm{ML}$ and HL plants over a period of 6-12 months, and in LL plants over a period of 18 months (Fig. 4). LL plants maintained a lower $\mathrm{LCP}_{\text {plant }}$ than ML and HL plants over the whole experiment, because they both had a much lower $\mathrm{LCP}_{\text {leaf }}$ (Fig. 4), a higher LIE (Fig. 2) and limited investments in stem and roots. It is very well possible that our LL plants would maintain a higher LIE beyond 2 years of time because they are expected to start turning over leaves (leaf life span range from c. 118 days for $P$. emetica to 870 for $P$. limonensis, Valladares et al. 2000) and may thus maintain similar amounts of leaf area over time by balancing production of leaves with loss of old leaves. Indeed, older and larger juvenile trees of canopy species reduce self-shading among leaves and maintain a high-light interception efficiency by such slow leaf production (Sterck et al. 2003), in spite of the shorter internodes supporting the new leaves (Sterck \& Bongers 2001). Such responses in architecture to light of seedlings (this study, see also Poorter \& Werger 1999) and juvenile trees (other studies) are predicted for trees that maximize that carbon returns over functional leaf life spans (Horn 1971) or over leaf- and sapwood life spans (Sterck \& Schieving 2007), and are in line with the carbon gain hypothesis (Givnish 1988).

\section{ECOLOGICAL CONSEQUENCES AT THE SEEDLING STAGE ACROSS SPECIES}

The 15 species of study belong to the genus Psychotria and all coexist as shrubs in a tropical forest understorey, where lowlight levels dominate. Nevertheless, 6 of 15 species have been categorized as gap-dependent species in an earlier study (Wright 1991). We observed that only one single species did not survive at the lowest light levels. This species ( $P$. emetica) had the shortest leaf life span (118 days, Valladares et al. 2000), relatively high biomass costs per leaf area (only two of the fifteen species had a $>10 \%$ higher leaf mass per area), and a large root system (see Fig. S5) suggesting that plants of this species could not pay back their leaf costs in time (see also Poorter et al. 2006). The remaining 14 species survived under all light levels and were apparently able to pay back leaf costs over their considerably longer leaf life spans (212-870 days). These results are consistent with the observation that leaf life span, rather than LMA or $\mathrm{A}_{\text {area, }}$ constrains the survival of plants in the shaded forest understorey of tropical forest (Sterck, Poorter \& Schieving 2006), but this may not be the case for deciduous seedling communities of temperate forests (Janse-ten Klooster, Thomas \& Sterck 2007).

For those 14 species surviving at all light levels, we observed that LL plants grew more rapidly for those species with a lower $\mathrm{LCP}_{\text {plant }}$ (Fig. 7). This positive impact of a lower $\mathrm{LCP}_{\text {plant }}$ on growth at low light resulted from interspecific variation in $\mathrm{LCP}_{\text {leaf }}$ and LIE (Fig. 5) but was not significantly related to size or biomass partitioning (SI Fig. 4). The whole-plant architecture had, however, a smaller impact than 

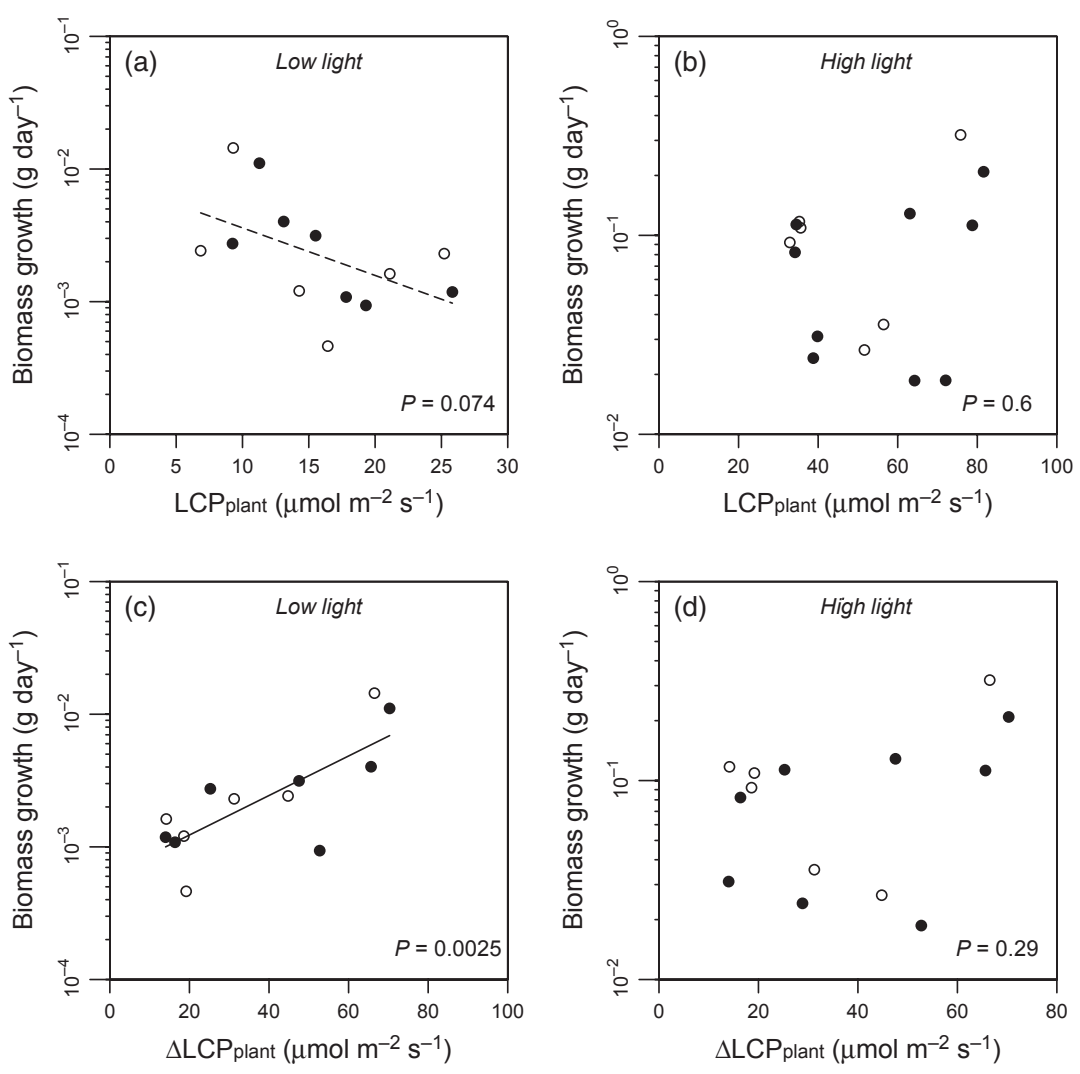

Fig. 7. Plant light compensation point $\left(\mathrm{LCP}_{\text {plant }}\right)$ impacts on the annual seedling growth of Psychotria species, under both low- and high-light level treatments. The $\log _{10}$ transformed species-specific values of estimated biomass growth rate over the first 100 days (for calculation, Method Section) were used in the regression analysis, and in the subfigures $y$-axes were $\log _{10}$ transformed accordingly. The significant linear trends are indicated with solid lines $(P<0.05)$ or dashed lines $(P<0.10)$. Species with a preference for gaps (Valladares et al. 2000) are indicated by open circles and those occurring in the forest understorey by solid black circles. See Fig. S3 for medium-light plant results.

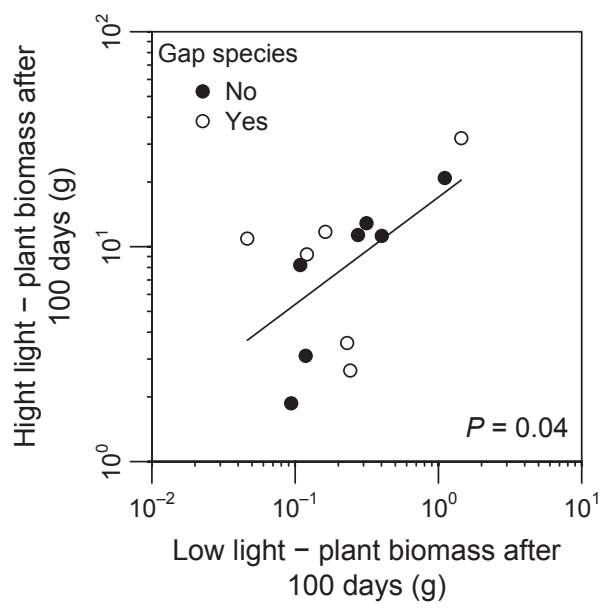

Fig. 8. The biomass growth rate averaged per species for the lowlight and high-light treatments for 14 Psychotria species from a Panamanian rain forest. Species with a preference for gaps (Valladares et al. 2000) are indicated by open circles, and those occurring in the forest understorey by solid black circles. Note $\log _{10}$ scale for both axes. The growth rates shown are the estimated biomass growth rates over the first 100 days (for calculation, Method Section).

leaf traits, whereas $\mathrm{LCP}_{\text {leaf }}$ varied by a factor of five across species, LIE varied by a factor of only two (Fig. 1d,e and Fig. 6a,b). The result confirms that leaf traits alone can have a significant impact on the growth rates of plants in the forest understorey (e.g. Sterck, Poorter \& Schieving 2006).

We tested whether species differences in $\mathrm{LCP}_{\text {plant }}$ drove trade-offs in growth between LL and HL conditions. Since
P. emetica was the single species that did not survive at LL, we did not find any evidence for a trade-off between survival and growth. For the other 14 species, which all survived LL, we observed that species that grew most rapidly at LL often grew most rapidly at HL as well (Fig. 8), which also contradicts the expected trade-off. We already discussed how the $\mathrm{LIE}, \mathrm{LCP}_{\text {leaf }}$ and $\mathrm{LCP}_{\text {plant }}$ drove across-species variation in growth at LL. At high light, a higher $\mathrm{A}_{\text {area }}$ and a greater total leaf area more than offset the negative impacts of a lower LIE. It thus seems that the species with the highest growth rates at LL conditions are those species that are most plastic in $\mathrm{LCP}_{\text {leaf }}$ and $\mathrm{LCP}_{\text {plant }}$ and that this plasticity more than compensates for the species-specific constraints on trait values for their growth at high light levels. The reported greater plasticity of gap species compared to understorey species (Bazzaz \& Carlson 1982; Strauss-debenedetti \& Bazzaz 1991; Lortie \& Aarssen 1996; Markesteijn, Poorter \& Bongers 2007) was not confirmed by our study.

Our results contrast with the view that differences in whole-plant light compensation point and underlying traits drive the separation of species across contrasting light environments. The fact that none of our results were related to observed preferences of species for (high light) gaps or (low light) closed forest sites (e.g. Fig. 7) does not support this view either. This is in contradiction with field studies that do show trade-offs in survival and growth rate at low and high light (Kobe 1996; Sterck, Poorter \& Schieving 2006). These latter studies included shade tolerant and intolerant canopy tree species, which possibly span a much larger range of 
shade tolerance and potential growth rates than the genus of understorey shrubs considered here.

The fact that 14 of 15 species survive the LL levels suggests that plants suffered insufficient light stress to demonstrate their real limits of tolerating shade. This is remarkable, even more so because five of the six species, that are considered dependent on gaps and the higher light levels associated with them (Wright 1991), survived and grew at LL levels that correspond with the most shaded conditions encountered in the actual forest understorey (Valladares et al. 2000). Partially, our choice of $<1.5$-year seedlings excludes larger, older juvenile phases, which may face a lower shade tolerance and greater gap dependency with increasing size. In addition, the watered and fertilized experimental conditions neglect the coupling between light, water and nutrient stress in real forest understories, where seedlings compete with the biggest resource consumers - large adult trees - for those resources (e.g. Coomes \& Grubb 2000). In line with this, it appears that light compensation points and shade tolerances of forest understorey plants cannot be estimated from light limitations of seedlings alone, but that limitations in the availability of water or nutrients and possible disturbances of understorey plants in different life phases should also be accounted for.

\section{Conclusions}

The plant light compensation point is a unifying concept for comparing shade tolerances across plants (Craine et al. 2012) but has been applied for across-species comparisons in only few cases (Baltzer \& Thomas 2007; Lusk et al. 2011; Sterck et al. 2011). Here, we used a new version of the Y-plant model (Pearcy, Duursma \& Falster 2011) to compare light compensation points of seedlings in different light conditions across 15 sympatric shrub species of a tropical forest understorey. Our results show that the plasticity in light compensation points and underlying leaf and architectural traits largely neutralizes the separation of light niches among the species of the studied forest understorey shrub genus. Moreover, our results imply that differential preferences of species for either gaps or the forest understorey are more critical in a later life phase, or are driven by other stress factors than low light alone.

\section{References}

Baltzer, J.L. \& Thomas, S.C. (2007) Determinants of whole-plant light requirements in Bornean rain forest tree saplings. Journal of Ecology, 95, 12081221

Bazzaz, F.A. \& Carlson, R.W. (1982) Photosynthetic acclimation to the variability in the light environment of early and late successional plants. Oecologia, 54, 313-316.

Cieslak, M., Lemieux, C., Hannan, H. \& Prusinkiewicz, P. (2008) Quasi-Monte Carlo simulation of the light environment of plants. Functional Plant Biology, 35, 837-849.

Coomes, D.A. \& Grubb, P.J. (2000) Impacts of root competition in forests and woodlands: a theoretical framework and a review of experiments. Ecological Monographs, 70, 171-207.

Craine, J.M., Engelbrecht, B.M.J., Lusk, C.H., McDowell, M.G. \& Poorter, H. (2012) Resource limitation, tolerance, and the future of ecological plant classification. Frontiers in Plant Science, 3, 1-10.
Delagrange, S., Montpied, P., Dreyer, E., Messier, C. \& Sinoquet, H. (2006) Does shade improve light interception efficiency? A comparison among seedlings from shade-tolerant and -intolerant temperate deciduous tree species. New Phytologist, 172, 293-304.

Duursma, R.A., Falster, D.S., Valladares, F., Sterck, F.J., Pearcy, R.W., Lusk, C.H. et al. (2012) Light interception efficiency explained by two simple variables: a test using a diversity of small- to medium-sized woody plants. New Phytologist, 193, 397-408.

Farque, L., Sinoquet, H. \& Colin, F. (2001) Canopy structure and light interception in Quercus petraea seedlings in relation to light regime and plant density. Tree Physiology, 21, 1257-1267.

Givnish, T. J. (1988) Adaptation to sun vs. shade: a whole-plant perspective. Australian Journal of Plant Physiology, 15, 63-92.

Horn, H.S. (1971) The Adaptive Geometry of Trees. Princeton University Press, Princeton.

Hubbell, S.P. (2005) Neutral theory in community ecology and the hypothesis of functional equivalence. Functional Ecology, 19, 166-172.

Hubbell, S.P. (2006) Neutral theory and the evolution of ecological equivalence. Ecology, 87, 1387-1398.

Janse-ten Klooster, S. H., Thomas, E. \& Sterck, F.J. (2007) Explaining interspecific differences in sapling growth and shade tolerance in temperate forests. Journal of Ecology, 95, 1250-1260.

Kobe, R.K. (1996) Intraspecific variation in sapling mortality and growth predicts geographic variation in forest composition. Ecological Monographs, 66, 181-201.

Lortie, C.J. \& Aarssen, L.W. (1996) The specialization hypothesis for phenotypic plasticity in plants. International Journal of Plant Sciences, 157, 484-487.

Lusk, C.H., Pérez-Millaqueo, M.M., Piper, F.I. \& Saldaña, A. (2011) Ontogeny, understorey light interception and simulated carbon gain of juvenile rainforest evergreens differing in shade tolerance. Annals of Botany, 108, 419-428.

Markesteijn, L., Poorter, L. \& Bongers, F. (2007) Light-dependent leaf trait variation in 43 tropical dry forest tree species. American Journal of Botany, 94, 515-525.

Markesteijn, L., Poorter, L., Paz, H., Sack, L. \& Bongers, F. (2011) Ecological differentiation in xylem cavitation resistance is associated with stem and leaf structural traits. Plant, Cell \& Environment, 34, 137-148.

Pearcy, R.W., Duursma, R.A., Falster, D.S. \& PrometheusWiki contributors. (2011) Studying Plant Architecture with Y-Plant and 3D Digitising. PrometheusWiki. [WWW document] URL: http://prometheuswiki.publish.csiro.au.

Pearcy, R. W., Muraoka, H. \& Valladares, F. (2005) Crown architecture in sun and shade environments: assessing function and trade-offs with a threedimensional simulation model. New Phytologist, 166, 791-800.

Pearcy, R. W. \& Yang, W. (1996) A three-dimensional crown architecture model for assessment of light capture and carbon gain by understorey plants. Oecologia, 108, 1-12.

Pearcy, R. W., Valladares, F., Wright, S. \& Lasso de Paulis, E. (2004) A functional analysis of the crown architecture of tropical forest Psychotria species: do species vary in light capture efficiency and consequently in carbon gain and growth? Oecologia, 139, 163-177.

Penning de Vries, F.W.T. (1975) The costs of maintenance processes in plants. Annals of Botany, 39, 77-92.

Poorter, L. \& Werger, M.J.A. (1999) Light environment, sapling architecture, and leaf display in six rain forest tree species. American Journal of Botany, 86, 1464-1473.

Poorter, H., Pepin, S., Rijkers, R., De Jong, Y., Evans, J.R. \& Körner, C. (2006) Construction costs, chemical composition and payback time of highand low-irradiance leaves. Journal of Experimental Botany, 57, 355-371.

Poorter, H., Niinemets, U., Poorter, L., Wright, I.J. \& Villar, R. (2009) Causes and consequences of variation in leaf mass per area (LMA): a meta-analysis. New Phytologist, 182, 565-588.

R Development Core Team (2012) R: A Language and Environment for Statistical Computing. R Foundation for Statistical Computing, Vienna, Austria. ISBN 3-900051-07-0, URL http://www.R-project.org.

Sterck, F.J. \& Bongers, F. (2001) Crown development in tropical rain forest trees: patterns with tree height and light availability. Journal of Ecology, 89, $1-13$.

Sterck, F.J., Poorter, L. \& Schieving, F. (2006) Leaf traits determine the growth-survival trade-off across rain forest tree species. American Naturalist, 167, 758-765.

Sterck, F.J. \& Schieving, F. (2007) 3-D Growth patterns of trees: effects of carbon economy, meristem activity, and selection. Ecological Monographs, 77, 405-420.

Sterck, F.J., Bongers, F., During, H.J., Martinez-Ramos, M.M. \& De Kroon, H. (2003) Module responses in a tropical forest tree analyzed with a matrix model. Ecology, 84, 2751-2761. 
Sterck, F.J., Markesteijn, L., Schieving, F. \& Poorter, L. (2011) Functional traits determine trade-offs and niches in a tropical forest community. Proceedings of the National Academy of Sciences, 108, 20627-20632.

Strauss-debenedetti, S. \& Bazzaz, F.A. (1991) Plasticity and acclimation to light in tropical moraceae of different successional positions. Oecologia, 87, 377-387.

Valladares, F. \& Niinemets, U. (2008) Shade tolerance, a key plant feature of complex nature and consequences. The Annual Review of Ecology, Evolution and Systematics, 39, 237-257.

Valladares, F., Skillman, J.B. \& Pearcy, R.W. (2002) Convergence in light capture efficiencies among tropical forest understory plants with contrasting crown architectures: a case of morphological compensation. American Journal of Botany, 89, 1275-1284.

Valladares, F., Wright, S.J., Lasso, E., Kitajima, K. \& Pearcy, R.W. (2000) Plastic phenotypic response to light of 16 congeneric shrubs from a Panamanian rainforest. Ecology, 81, 1925-1936.

Veneklaas, E.J. \& Poorter, L. (1998) Growth and carbon partitioning of tropical tree seedlings growing in contrasting light environments. Inherent Variation in Plant Growth. Physiological Mechanisms and Ecological Consequences (eds H. Lambers, H. Poorter \& M.I. van Vuuren), pp. 337-361. Backhuys Publishers, Leiden, the Netherlands.

Walters, M.B. \& Reich, P.B. (1999) Low-light carbon balance and shade tolerance in the seedlings of woody plants: do winter deciduous and broad-leaves evergreen species differ? New Phytologist, 143, 143-154.

Warton, D.I., Duursma, R.A., Falster, D.S. \& Taskinen, S. (2012) SMATR 3 an R package for estimation and inference about allometric lines. Methods in Ecology and Evolution, 3, 257-259.
Wright, S.J. (1991) Seasonal drought and the phenology of understory shrubs in a tropical moist forest. Ecology, 72, 1643-1657.

Received 16 July 2012; accepted 30 January 2013

Handling Editor: Matthew Turnbull

\section{Supporting Information}

Additional Supporting Information may be found in the online version of this article:

Figure S1. The 3D development of seedlings.

Figure S2. STAR and LIE values compared.

Figure S3. $\mathrm{LCP}_{\text {leaf }}$ and $\mathrm{LIE}$ impacts on $\mathrm{LCP}_{\text {plant }}$ for medium-light plants.

Figure S4. Leaf mass to total plant mass ratio impacts on $\mathrm{LCP}_{\text {plant }}$.

Figure S5. Respiration estimates of foliage, stem and roots. 